\title{
Characteristics of Aboriginal and Torres Strait Islander smokers exposed to anti-smoking marketing in South Australia.
}

Joshua Trigg ${ }^{\mathrm{a} *}$, Damien Shen ${ }^{\mathrm{b}}$, Julia Morris ${ }^{\mathrm{c}}$, and Jason Blunt ${ }^{\mathrm{c}}$

${ }^{a}$ College of Medicine and Public Health, Flinders University, Bedford Park, Australia; ${ }^{b}$ SA Health, Adelaide, Australia; 'Behavioural Research Unit, Cancer Council South Australia, Adelaide, Australia

\section{Author details:}

*Correspondence concerning this article should be addressed to Joshua Trigg, College of Medicine and Public Health, Flinders University, Sturt Road, Bedford Park, SA 5042, Australia. Contact: joshua.trigg@flinders.edu.au +61882914171. ORCID: https://orcid.org/0000-0002-8173-5791

Damien Shen, Department for Health and Wellbeing, SA Health, 11 Hindmarsh Square, Adelaide SA 5000, Australia. Contact: damien.shen@sa.gov.au

Julia Morris, Behavioural Research and Evaluations Unit, Cancer Council SA, 202 Greenhill Road, Eastwood, SA 5063, Australia. Contact: jmorris@cancersa.org.au. ORCID: https://orcid.org/0000-0003-2519-2400

Jason Blunt, Behavioural Research and Evaluations Unit, Cancer Council SA, 202 Greenhill Road, Eastwood, SA 5063, Australia. Contact: jblunt@,cancersa.org.au Ethical approvals were obtained from the Aboriginal Health Research Ethics Committee (AHREC: 04-17-777; AHREC: 04-17-778), and SA Health Human Research Ethics Committee (HREC/18/SAH/94, SSA/18/NALHN/113; SSA/18/SAC/284).

\section{Funding details}

This research was supported by SA Health under a service agreement [DHA 2012-08449].

\section{Disclosure statement}

No potential conflict of interest was reported by the authors.

Word count: 5190 


\section{Abstract}

Background: Smoking is disproportionately prevalent among Aboriginal and Torres Strait Islander Australian peoples, with 39\% of Indigenous Australians aged over 15 years smoking daily. Efforts to reduce this high prevalence include culturally focused media campaigns, designed using community consultation, highlighting the need to determine how such health messaging is received by smokers. This study aimed to examine Indigenous Australian smokers' reactions to a culturally focused anti-smoking mass media campaign-'Give up Smokes'. Methods: Intercept surveying across health services and events used recorded demographics, smoking status, quit attempts, smoking health effects, anti-smoking campaign recall, social support, and campaign reactions. Participants rated campaign images in five domains: 1) whether it made them stop and think; 2) personal relevance; 3) believability of design and message; 4) prompting concern about smoking; and 5) motivation towards quitting. Cluster analysis was used to segment smoker types. Results: Smoking health effects knowledge was high, and did not differ by quit readiness, attempts, or social support. Cessation support access was higher among those with greater readiness to quit. Social smoking behaviour and confidence to support others quitting did not significantly differ between participants, however importance of others quitting did. Quit readiness, attempts, and social support were associated with reaction to campaign design, but not message recall. Four types of smokers were described, using smoking characteristics, who differed in campaign message reactions. Conclusions: Strategies using campaign-exposed smoker characteristics to inform culturally focused health promotion are discussed in relation to four identified types of smokers.

Keywords: Indigenous health, smoking, social marketing, tobacco, messaging 


\section{Introduction}

\subsection{Background}

Smoking continues to be disproportionately prevalent among Aboriginal and Torres Strait Islander Australian peoples (hereafter, Indigenous Australians). Recent data show that $39 \%$ of Indigenous Australians aged over 15 years are smoking daily, compared to $14 \%$ of nonIndigenous Australians (van der Sterren, Greenhalgh, Knoche, \& Winstanley, 2018), and that the former are 2.7 times more likely to begin smoking than non-Indigenous Australians (Australian Institute of Health and Welfare, 2018). This has contributed to a national prevalence gap of approximately 30\% between 1995 and 2014 (van der Sterren, et al., 2018). Health risk disparity is further compounded by social determinants such as socioeconomic disadvantage and discrimination (Australian Institute of Health and Welfare, 2016). Indigenous Australians may also struggle more with cessation attempts, as social exposure to smoking is associated with a lower likelihood of successful quitting (Thomas et al., 2019). These issues underscore the ongoing need for community-based support initiatives for smoking cessation, and for effective social campaigning to promote quit supports and services to Indigenous Australians interested in accessing them.

One frequently used approach to reducing tobacco consumption is anti-smoking mass-media campaigns. In health promotion contexts, these are commonly used to expose a majority of the population via existing media (i.e. print, television, social media or radio advertising) to a health message (Wakefield, Loken, \& Hornik, 2010). In this sense, exposure to such messages is passive (Wakefield, et al., 2010), meaning that campaigns must be designed to effectively influence a range of consumers. In terms of smoking cessation activities, antismoking campaigns can attempt to be attention grabbing and thought provoking, to facilitate audience processing of the message (Noar et al., 2017). This effect is illustrated in the case of 
cigarette packet warnings, where stronger warnings increase attention and message processing (e.g., cognitive elaboration) (Noar, et al., 2017). However, the features of attention and thought provoking advertising can have variable effects. Among non-Indigenous populations, anti-smoking advertisements that show smoking cues (e.g., cigarette packets) are associated with increased visual attention and processing (Clayton, Leshner, Bolls, \& Thorson, 2017; Sanders-Jackson et al., 2011). However, if this is paired with negative visceral imagery (e.g., depicting health harms), a reduction in attention (Sanders-Jackson, et al., 2011) or increased defensive message processing (Clayton, et al., 2017) can occur.

Personal relevance of the campaign message can also play a role. Previous research with Indigenous Australian participants has shown that personally relevant messaging predicts positive attitudes towards culturally tailored anti-smoking advertisements (Stewart et al., 2011). Similarly, believability of anti-smoking messages is also shown as predictive of more positive attitudes towards the message (O'Cass and Griffin, 2006), and thus increasing believability may increase message impact. Additionally, the use of emotive messages that provide reasons to quit smoking has been supported in use with non-Indigenous Australian smokers, where providing examples of reasons to quit resonates more effectively with the audience than describing how to quit (Guillaumier et al., 2017).

\subsection{Culturally targeted anti-smoking social marketing}

Studies have demonstrated that when targeting Indigenous Australian populations, smoking cessation messages have better reach (Kubacki and Szablewska, 2017; Nicholson et al., 2017) and are preferred by consumers (Gould, McEwen, Watters, Clough, \& Zwan, 2013) if they are appropriately culturally targeted. Anti-smoking campaigns designed for Indigenous Australian populations are constantly evolving to consider cultural factors that potentially increase message resonance, audience engagement, and message processing. It's suggested 
that health messaging needs to, where possible, acknowledge community-level characteristics of different Aboriginal and Torres Strait Islander audiences that relate to facilitators of effective social marketing campaigns (Madill, Wallace, Goneau-Lessard, MacDonald, \& Dion, 2014). To address this, social marketing strategies can incorporate formative research, identify focal behaviours, or perform audience segmentation (Kubacki and Szablewska, 2017). Audience segmentation or clustering, treats audiences as multidimensional to tailor campaign messages to distinct subpopulations (Hardcastle and Hagger, 2016). Within antismoking social campaigns, this is essential to effectively target specific Indigenous Australian subpopulations, particularly current smokers.

\subsection{Aims and objectives}

This study explores characteristics and reactions of Indigenous Australian smokers exposed to a mass-media culturally targeted anti-smoking campaign, 'Give up Smokes' between January 2018 and June 2019 in terms of their demographic characteristics, readiness and intention to quit, quit attempts and social support.

\section{Methods}

\section{1. 'Give up smokes' campaign}

The 'Give up Smokes' (GUS) campaign is a South Australian initiative created in 2010 to raise awareness of tobacco smoking harms, as well as smoking cessation supports and services among Indigenous Australians (Maksimovic, Shen, Bandick, Ettridge, \& Eckert, 2015). The campaign includes emotive-focused imagery (Figure 1) disseminated via outdoor advertising (e.g., events, buses, bus stops), and digitally (e.g., Facebook, website). Key messaging in the campaign focused on personal (i.e. health, financial) consequences, the impact of smoking on family, quitting benefits, seeking quit support, and quit attempts. This 
messaging was designed based on qualitative evaluation of the most recent previous campaign, and on the health messaging aims. Messages informed creative design, such as integrating images of children (i.e. representing impact on family).

\subsection{Participants}

The targeted audience for the campaign were Indigenous Australian smokers aged 18-39 years residing in Southern and Northern metropolitan areas of South Australia. Participants were recruited across six Aboriginal health services (Southern suburbs, $n=23$; Northern suburbs, $n=239$ ), and two community events (sporting event, $n=36$; college open day, $n=$ 25). Participants for the final analysis comprised only current smokers who had been exposed to the GUS campaign. Exposure comprised prompted or unprompted recall of encountering the campaign via planned channels, including physical (e.g., bus stops) and online spaces (e.g., Facebook).

\subsection{Materials}

A 19-item intercept survey collected demographics and assessed recall of anti-smoking campaigning, and reactions and feeling towards the GUS campaign. Participants rated four key campaign images (see Figure 1) from 1 'strongly disagree' to 4 'strongly agree' in five reaction domains: 1) thought, the extent to which it made them stop and think; 2) relevance, feeling that it was personally applicable; 3) believability, whether design and message were believable; 4) concern, if it prompted concern about their own smoking; and 5) motivation, if it prompted consideration of quitting. Items were Likert-rated or check-box.

Participants indicated their smoking behaviour as daily, weekly, occasional, ex-smoker, or non-smoker. Participants indicated knowledge of smoking and passive-smoking related illnesses as yes/no, and described associated illnesses. Cessation support access was 
measured by use of the following in a quit attempt: calling a quit support phone service, asking a doctor or another health professional for assistance, visiting a quit support website, or using nicotine replacement therapies. Contextual smoking factors included allowing smoking in their home or car, speaking with family or friends about quitting in the last six weeks, confidence in supporting others to quit smoking, and perceived importance of close others (family or friends) quitting smoking. Message recall was indicated by describing an anti-smoking message from the campaign to think about family impacts, think about costs, or 'Think. Quit,' the campaign tagline.

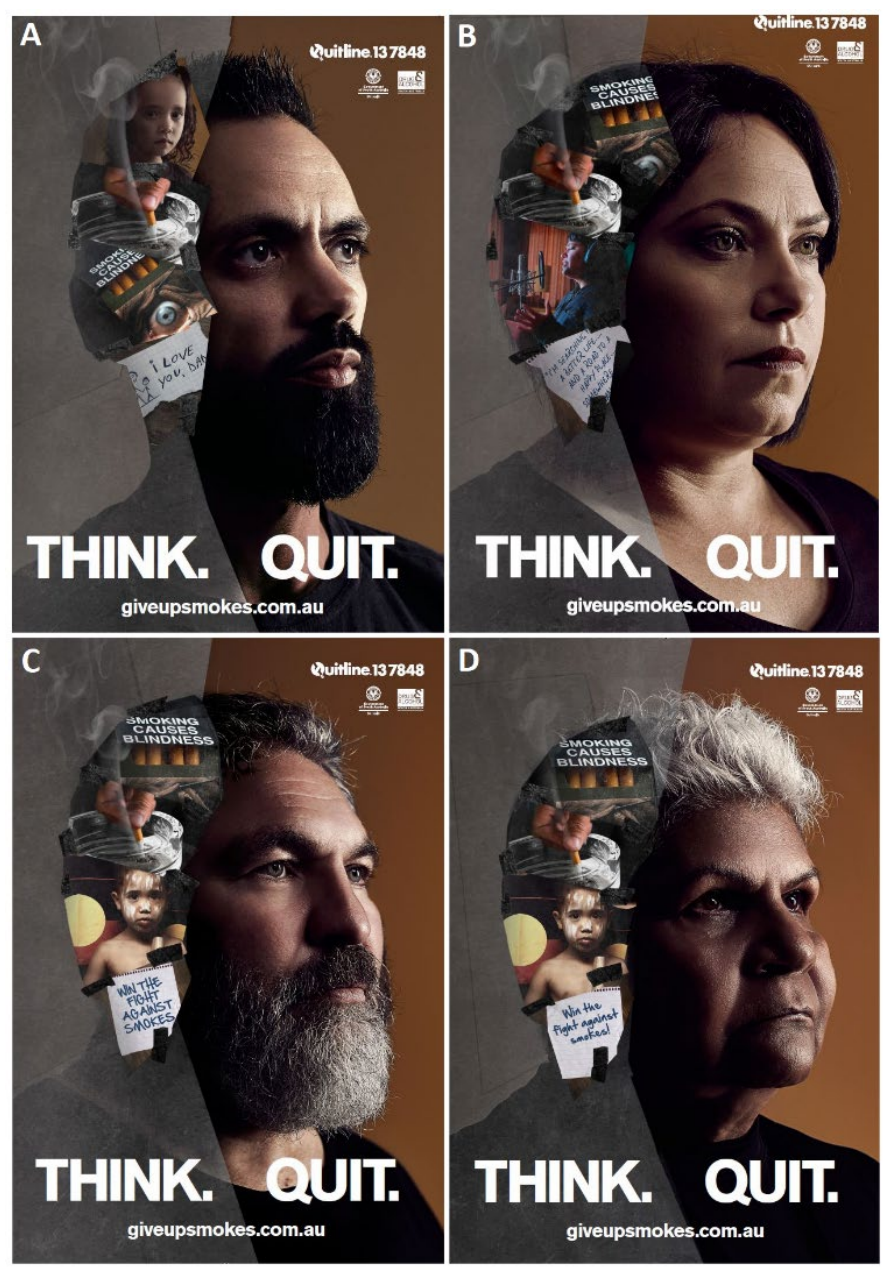

Figure 1. Anti-smoking social marketing campaign materials: (A) Jack, (B) Nancy, (C) Michael, and (D) Sharon. 


\subsection{Procedure}

Face-to-face intercept surveys were administered by research assistants across health services and community events. At health services, research assistants in waiting areas offered visitors the opportunity to complete the survey, or were approached by visitors. Verbal consent for anonymous surveying was required, and a gift card draw incentive was available at each location. Ethical approvals were obtained from the Aboriginal Health Research Ethics Committee (AHREC: 04-17-777; AHREC: 04-17-778), and SA Health Human Research Ethics Committee (HREC/18/SAH/94, SSA/18/NALHN/113; SSA/18/SAC/284).

\subsection{Data analysis}

Two-step cluster analysis was used to classify participants who currently smoked and who had been exposed to the campaign (SPSS v. 23) according to their smoking behaviour characteristics: quit attempts, social support, intention to quit, and readiness to quit. This included having made a quit attempt in the past 12 months (quit attempts), having discussed quitting with family or friends in the past six weeks (social support), intention to quit in the following 12 months (intention to quit), and participant readiness to quit in the next 12 months (readiness to quit).

The sample size of smokers was adequate for descriptive clustering ( $p \leq .05$, power $\geq 50 \%$ ) (Hoenig and Heisey, 2001), exceeding the suggested two to the power of the number of clustering variables (Foreman, 1984). Participants were grouped as pre-clusters, assessed for similarity using the log-likelihood function, then grouped as clusters based on maximum similarity, with pattern fit indicated by a silhouette coefficient. Welch's ANOVA, and Games-Howell post-hoc tests were used for analyses. Screening revealed two influential cases for number of quit attempts and these were recoded to the nearest lower case value (i.e. Mahalanobis, Cooks and leverage). A maximum of five clusters was set for parsimony, with 
a 4-cluster model accepted, and an average silhouette coefficient indicating adequate model fit $\left(s_{\mathrm{c}}=.50\right)$. Analyses were conducted on cases with complete data on required variables.

\section{Results}

\subsection{Sample profile}

Demographic characteristics of campaign-exposed smokers are displayed in Table 1. Of the 323 Indigenous Australians first surveyed, 86 were non-smokers (non-smoking/never smoked), 80 were ex-smokers, and five refused. Remaining participants who were both exposed to the campaign and current smokers $(n=103,31.9 \%$ of original sample), were predominately female $(62.0 \%)$, middle aged; $(\mathrm{M} \pm \mathrm{SD}=41.4 \pm 13.4$ years $)$; and resided in urban metropolitan areas $(89.3 \%)$.

Table 1. Summary of demographic and smoking characteristics of campaign-exposed smokers.

\begin{tabular}{|c|c|}
\hline & $\begin{array}{l}\text { Campaign-exposed smokers } \\
\qquad(n=103)\end{array}$ \\
\hline Gender (female) & $62.00 \%$ \\
\hline Age in years, $\mathrm{M} \pm \mathrm{SD}$ & $41.36 \pm 13.42$ \\
\hline Target age-range 18-39 years (yes) & $46.08 \%$ \\
\hline \multicolumn{2}{|l|}{ Remoteness } \\
\hline Metropolitan & $89.32 \%$ \\
\hline Regional & $2.91 \%$ \\
\hline Remote & $3.88 \%$ \\
\hline Refused & $3.88 \%$ \\
\hline \multicolumn{2}{|l|}{ Smoking frequency } \\
\hline Daily & $72.82 \%$ \\
\hline Weekly & $12.62 \%$ \\
\hline Occasional (less than weekly) & $14.56 \%$ \\
\hline \multicolumn{2}{|l|}{ Quitting characteristics } \\
\hline Plan to quit in the next 12 months (yes) & $74.76 \%$ \\
\hline Quit attempt in the past 12 months (yes) & $64.89 \%$ \\
\hline Quit attempts in past 12 months, $\mathrm{M} \pm \mathrm{SD}$ & $1.59 \pm 2.42$ \\
\hline \multicolumn{2}{|l|}{ Lack of socioeconomic disadvantage $^{\wedge}$} \\
\hline Average decile, $\mathrm{M} \pm \mathrm{SD}$ & $3.24 \pm 0.21$ \\
\hline Low $(1-3)$ & $58.25 \%$ \\
\hline Moderate (4-7) & $37.86 \%$ \\
\hline High (8-10) & $3.88 \%$ \\
\hline
\end{tabular}


Of the exposed smoker sample, $46.1 \%$ were in the targeted campaign audience (i.e. aged 18 39 years). Participants were from locations of lower socioeconomic advantage. Current smokers who had attempted quitting in the past 12 months were significantly more likely to report planning a quit attempt in the next year $(83.6 \%)$ than those who had not attempted in the previous 12 months $(57.6 \%)\left(\chi^{2}(1, n=94)=7.63, p=.006, \phi=.29\right)$.

\subsection{Clustering smokers}

Cluster characteristics are shown in Table 2 and based on campaign-exposed current smokers $(n=90)$. Gender did not differ significantly across clusters $\left(\chi^{2}(3, n=88)=1.30, p=.728, V\right.$ $=.12)$.

Cluster 1 -Ready, intent attempters: This cluster represented $15.6 \%$ of participants, all of whom planned to quit in the next 12 months, had attempted quitting at least once in the previous 12 months, had an average of three past quit attempts $(\mathrm{M} \pm \mathrm{SD}=2.71 \pm 1.07)$, had not discussed quitting with family or friends, and who demonstrated a slight readiness to quit $(\mathrm{M} \pm \mathrm{SD}=2.64 \pm 1.01)$. This cluster were younger than other smokers $(\mathrm{M} \pm \mathrm{SD}=38.00 \pm 12.16$ years), and the majority were female (71.43\%).

Cluster 2 - Unready, potential attempters: This cluster comprised participants (25.6\%) who were not planning to quit smoking in the next 12 months, had an average of 1 quit attempt $(\mathrm{M} \pm \mathrm{SD}=0.87 \pm 1.33)$, and identified as not ready to quit $(\mathrm{M} \pm \mathrm{SD}=2.17 \pm 0.72)$. Less than half of these participants had attempted to quit at least once within the past 12 months $(43.5 \%)$ and had discussed quitting with their family and friends (30.4\%). Similar to cluster 1, these smokers were younger $(\mathrm{M} \pm \mathrm{SD}=37.78 \pm 12.01$ years $)$ and were relatively equivalent in terms of gender $($ female $=56.52 \%)$.

Cluster 3 - Ready, connected attempters: Cluster 3 (38.9\% of sample) stated they intended to 
quit over the next 12 months, had attempted to do so at least twice in the previous 12 months $(\mathrm{M} \pm \mathrm{SD}=2.51 \pm 3.34)$, had spoken with family or friends about quitting, and displayed a moderately strong readiness to quit. These smokers were largely middle-aged $(\mathrm{M} \pm \mathrm{SD}=$ $41.83 \pm 13.01$ years) females $(67.7 \%)$, and reported significantly higher quit readiness than unready, potential attempters (Table 2).

Cluster 4 - Connected, new attempters: Cluster 4 comprised $20.0 \%$ of participants, all of whom stated an intent to quit over the next 12 months and had not attempted to do so in the previous 12 months. Participants in this cluster were mostly middle-aged $(\mathrm{M} \pm \mathrm{SD}=$ 47.17 \pm 13.47$)$ and females (70.6\%). Half had spoken with family or friends about quitting, and $38.9 \%$ had accessed smoking supports and services. Within this group, participants reported a slight readiness to quit $(\mathrm{M} \pm \mathrm{SD}=2.61 \pm 0.85)$.

\subsection{Health, illness knowledge, and support access}

Across the four types of smokers, participants did not significantly differ in accessing health checks with a medical professional, with approximately half of each cluster having done so in the previous year. Although non-significant, this was slightly higher among ready, connected attempters. Agreement that smoking and passive smoking are associated with illnesses did not significantly differ across clusters, though this was slightly higher in unready, potential attempters: respondents with no reported quit intentions and low readiness to quit. Accessing smoking cessation supports and services differed significantly between each group $\left(\chi^{2}(3, n=\right.$ $90)=7.99, p=.046, V=.30)$. Support access was highest among ready, connected attempters (65.7\%) and ready, intent attempters (42.9\%), followed by connected, new attempters (38.9\%), and unready, potential attempters (30.43\%). 
Table 2. Summary of cluster characteristics on cluster defining and reaction domain variables for Indigenous Australian smokers exposed to the anti-smoking social marketing initiative $(n=90)$.

\begin{tabular}{|c|c|c|c|c|c|c|c|c|}
\hline \multirow[b]{2}{*}{ Characteristic } & \multirow{2}{*}{$\begin{array}{c}\begin{array}{c}\text { Ready, } \\
\text { intent } \\
\text { attempters } \\
(n=14)\end{array} \\
\%\end{array}$} & \multirow{2}{*}{ 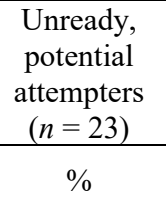 } & \multirow{2}{*}{$\begin{array}{c}\begin{array}{c}\text { Ready, } \\
\text { connected } \\
\text { attempters } \\
(n=35)\end{array} \\
\%\end{array}$} & \multirow{2}{*}{ 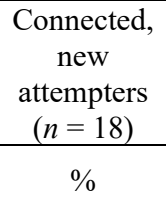 } & \multicolumn{4}{|c|}{$\begin{array}{c}\text { Test of intercluster } \\
\text { differences }\end{array}$} \\
\hline & & & & & $\chi^{2}$ & $d f / n$ & $p$ & $V$ \\
\hline $\begin{array}{l}\text { Plan to quit in next } \\
12 \text { months (yes) }{ }^{\dagger \wedge}\end{array}$ & 100.00 & 0.00 & 100.00 & 100.00 & - & - & - & - \\
\hline $\begin{array}{l}\text { Quit attempt in past } \\
12 \text { months (yes) } \dagger \wedge\end{array}$ & 100.00 & 43.48 & 100.00 & 0.00 & - & - & - & - \\
\hline $\begin{array}{l}\text { Spoken about } \\
\text { quitting (yes) }{ }^{\dagger}\end{array}$ & $0.00^{\mathrm{a}}$ & $30.43^{b}$ & $100.00^{c}$ & 50.00 & 51.84 & $3 / 90$ & .001 & .76 \\
\hline $\begin{array}{l}\text { Allow smoking in } \\
\text { house (yes) }\end{array}$ & 35.71 & 26.09 & 37.14 & 22.22 & 1.67 & $3 / 90$ & .644 & .14 \\
\hline $\begin{array}{l}\text { Allow smoking in } \\
\text { car (yes) }\end{array}$ & 30.77 & 40.91 & 26.67 & 25.00 & 1.55 & $3 / 81$ & .672 & .14 \\
\hline $\begin{array}{l}\text { Health check } \\
\text { (yes) }\end{array}$ & 54.55 & 52.63 & 65.62 & 50.00 & 1.46 & $3 / 78$ & .692 & .14 \\
\hline $\begin{array}{l}\text { Smoking illness } \\
\text { (aware) }\end{array}$ & 85.71 & 91.30 & 85.71 & 88.90 & 0.48 & $3 / 90$ & .923 & .07 \\
\hline $\begin{array}{l}\text { Passive smoking } \\
\text { illness (aware) }\end{array}$ & 71.43 & 91.30 & 85.71 & 83.33 & 2.69 & $3 / 90$ & .442 & .17 \\
\hline Characteristic & $\mathrm{M} \pm \mathrm{SD}$ & $\mathrm{M} \pm \mathrm{SD}$ & $\mathrm{M} \pm \mathrm{SD}$ & $\mathrm{M} \pm \mathrm{SD}$ & $F$ & $d f / n$ & $p$ & $\eta^{2}$ \\
\hline $\begin{array}{l}\text { Readiness to quit } \\
\text { smoking }{ }^{\dagger}\end{array}$ & $2.64 \pm 1.01$ & $2.17 \pm 0.72^{\mathrm{a}}$ & $3.14 \pm 0.91^{\mathrm{b}}$ & $2.61 \pm 0.85$ & 6.57 & $3 / 38$ & .001 & .17 \\
\hline \multicolumn{9}{|l|}{ Jack } \\
\hline Thought & $2.86 \pm 1.17$ & $2.74 \pm 0.86^{\mathrm{a}}$ & $3.26 \pm 0.70$ & $3.39 \pm 0.50^{\mathrm{b}}$ & 3.39 & $3 / 38$ & .028 & .10 \\
\hline Relevance & $3.07 \pm 1.00$ & $2.73 \pm 0.77$ & $3.14 \pm 0.81$ & $3.33 \pm 0.59$ & 2.60 & $3 / 38$ & .066 & .07 \\
\hline Believability & $2.93 \pm 1.21$ & $3.13 \pm 0.34$ & $3.23 \pm 0.73$ & $3.44 \pm 0.51$ & 1.86 & $3 / 36$ & .153 & .05 \\
\hline Concern & $2.92 \pm 1.12$ & $3.00 \pm 0.85$ & $3.26 \pm 0.78$ & $3.17 \pm 0.79$ & 0.62 & $3 / 36$ & .609 & .02 \\
\hline Motivation & $2.69 \pm 1.25$ & $2.87 \pm 0.76)$ & $3.20 \pm 0.83$ & $3.11 \pm 0.76$ & 1.16 & $3 / 36$ & .338 & .05 \\
\hline \multicolumn{9}{|l|}{ Nancy } \\
\hline Thought & $2.86 \pm 1.03$ & $2.68 \pm 0.72$ & $3.09 \pm 0.82$ & $3.28 \pm 0.67$ & 2.61 & $3 / 38$ & .066 & .07 \\
\hline Relevance & $3.14 \pm 0.86$ & $2.71 \pm 0.78$ & $2.88 \pm 0.91$ & $3.17 \pm 0.71$ & 1.44 & $3 / 39$ & .246 & .04 \\
\hline Believability & $3.07 \pm 0.91$ & $3.09 \pm 0.29$ & $3.12 \pm 0.69$ & $3.22 \pm 0.55$ & 0.28 & $3 / 36$ & .840 & .01 \\
\hline Concern & $2.46 \pm 0.88$ & $2.62 \pm 0.74$ & $3.03 \pm 0.90$ & $3.11 \pm 0.68$ & 2.76 & $3 / 37$ & .056 & .09 \\
\hline Motivation & $2.69 \pm 1.11$ & $2.48 \pm 0.68$ & $3.00 \pm 0.89$ & $3.06 \pm 0.73$ & 2.84 & $3 / 36$ & .051 & .08 \\
\hline \multicolumn{9}{|l|}{ Michael } \\
\hline Thought & $2.93 \pm 1.00$ & $2.86 \pm 0.56^{\mathrm{a}}$ & $3.37 \pm 0.65^{\mathrm{b}}$ & $3.28 \pm 0.58$ & 3.68 & $3 / 37$ & .021 & .10 \\
\hline Relevance & $3.13 \pm 0.77$ & $2.81 \pm 0.68$ & $3.34 \pm 0.73$ & $3.22 \pm 0.65$ & 2.57 & $3 / 38$ & .061 & .08 \\
\hline Believability & $3.14 \pm 0.86$ & $2.95 \pm 0.49$ & $3.23 \pm 0.65$ & $3.33 \pm 0.49$ & 2.14 & $3 / 38$ & .112 & .05 \\
\hline Concern & $2.62 \pm 0.96$ & $2.82 \pm 0.59$ & $3.14 \pm 0.69$ & $3.11 \pm 0.76$ & 1.93 & $3 / 35$ & .143 & .07 \\
\hline Motivation & $2.54 \pm 0.97$ & $2.77 \pm 0.61$ & $3.11 \pm 0.68$ & $3.06 \pm 0.80$ & 2.11 & $3 / 35$ & .117 & .08 \\
\hline \multicolumn{9}{|l|}{ Sharon } \\
\hline Thought & $3.07 \pm 1.07$ & $3.09 \pm 0.53$ & $3.40 \pm 0.69$ & $3.28 \pm 0.67$ & 1.29 & $3 / 37$ & .291 & .04 \\
\hline Relevance & $3.29 \pm 0.91$ & $2.95 \pm 0.67$ & $3.31 \pm 0.80$ & $3.17 \pm 0.62$ & 1.16 & $3 / 38$ & .338 & .04 \\
\hline Believability & $3.07 \pm 0.92$ & $3.09 \pm 0.68$ & $3.34 \pm 0.73$ & $3.28 \pm 0.46$ & 0.76 & $3 / 38$ & .526 & .03 \\
\hline Concern & $2.68 \pm 1.03$ & $3.05 \pm 0.65$ & $3.34 \pm 0.77$ & $3.17 \pm 0.71$ & 1.72 & $3 / 36$ & .180 & .08 \\
\hline Motivation & $2.77 \pm 1.09$ & $2.95 \pm 0.65$ & $3.31 \pm 0.76$ & $3.00 \pm 0.77$ & 1.73 & $3 / 35$ & .179 & .06 \\
\hline
\end{tabular}

Note: ${ }^{\dagger}$ Clustering variable. ${ }^{\wedge}$ No test performed due to low expected cell count. One-way Welch’s ANOVA and Games-Howell post-hoc contrasts (superscript letters denote significant difference, $p<.05$ ). Chi-square used adjusted standardised residuals.

\subsection{Contextual factors}

Proportions of 'accepted' smoking behaviours varied markedly between the clusters, however 
these differences were not statistically significant (Table 2). Smoking in the home ranged from $22.2 \%$ (connected, new attempters) to $37.1 \%$ (ready, connected attempters). Smoking in cars ranged from $25.0 \%$ (connected, new attempters) to $40.9 \%$ (unready, potential attempters). Participants also rated how important it was to them that their friends and family who smoked quit, and how comfortable they felt in their ability to support them during an attempt. Confidence in ability to support others did not differ significantly across clusters ( $p$ $=.408)$. However, importance of close others quitting did significantly differ $(F(3,85)=$ $\left.4.79, p=.004, \eta^{2} .15\right)$. Ready, connected attempters $(\mathrm{M} \pm \mathrm{SD}=3.65 \pm 0.60)$ considered this more important than did unready, potential attempters $(\mathrm{M} \pm \mathrm{SD}=2.81 \pm 1.03)$ and connected, new attempters $(\mathrm{M} \pm \mathrm{SD}=3.00 \pm 0.79)$.

\subsection{Campaign reactions}

Reaction to the four campaign designs differed significantly in one domain: thought, defined as the extent to which it made respondents stop and think. Connected, new attempters rated the Jack design (Figure 1, A) as significantly more thought provoking (3.39 \pm 0.50$)$ than did unready, potential attempters (2.74 \pm 0.86$)$. Connected, new attempters also rated the Michael design (Figure 1, C) as significantly more thought provoking (3.37 \pm 0.65$)$ than did unready, potential attempters $(2.86 \pm 0.56)$. For the Nancy design (Figure 1, B), connected, new attempters found this more motivating $(3.06 \pm 0.73)$ than did unready, potential attempters (2.48 \pm 0.68$)$. However, as univariate and post-hoc tests did not meet the alpha criterion, this requires further examination.

Univariate tests of the remaining domains - relevance, believability, concern and motivation-identified no significant differences. However, in each of these reaction domains, average ratings were positive (i.e. $>2$ ), indicating that each type of smoker considered each of the four designs personally relevant, believable, and that it prompted 
concern about their own smoking, and would motivate them to quit.

\subsection{Message recall}

Message-related recall was high and did not significantly differ across clusters of campaign exposed smokers $\left(\chi^{2}(3, n=75)=3.63, p=.304, \phi=.22\right)$ : ready, intent attempters $(90.0 \%)$; unready, potential attempters (70.0\%); ready, connected attempters $(80.0 \%)$; and connected, new attempters $(60.0 \%)$.

\section{Discussion and conclusions}

This study examined characteristics and reactions of current smokers exposed to a culturally targeted anti-smoking campaign designed for Indigenous Australians in metropolitan South Australia. This included reaction to four anti-smoking campaign designs. Four distinct profiles of current smokers were identified, as characterised by their intent to quit in the next 12 months, having attempted quitting in the previous 12 months, speaking with family and friends about quitting in the past six weeks and stated level of readiness to quit smoking.

\subsection{Ready, intent attempters}

Ready, intent attempters were the least common type of smoker, who had attempted and planned to quit, though did not discuss this with others. They did not often seek assistance from quit supports or services and were only slightly ready to quit. Accessing dedicated quit resources at health services is associated with higher quit attempt likelihood in the previous year (Nicholson, Borland, Davey, Stevens, \& Thomas, 2015a). Therefore, these smokers may benefit from campaigns that highlight available community-based initiatives that provide resources and increase supportive contact, as opposed to expecting consumers to seek support independently. 
Given the lower supportive contact use by these smokers, campaigns might promote strategies for engaging with family and friends in ways that assist their quit attempt (e.g., boundary setting). As smoking can be socially normative in Indigenous Australians communities (Wright, 2018), campaign designs should promote resilience via calls to action that develop skills that support quitting and non-smoking in others (Tsourtos et al., 2014; Tsourtos et al., 2019).

Ready, intent attempters found the Michael and Sharon designs to be most thought provoking and personally relevant, and the Nancy and Sharon designs most believable. It is possible that the presence of authoritative elders and female models may have resonated with this type of smoker, reflecting the need to acknowledge cultural schemas, such as elder respect, in health messaging engaging Indigenous Australian smokers (Kendall and Barnett, 2015).

\subsection{Unready, potential attempters}

Approximately one in four smokers surveyed were unready, potential attempters. These smokers self-identified as being unready to quit and having no plan to quit, with only one in four having spoken with family or friends about quitting, and displaying low concern about close others quitting. Two in five had attempted quitting once in the past 12 months, and very few had accessed supports and services to do so. A large proportion of this cluster allowed others to smoke in their car, and a smaller proportion in their house. Despite this acceptance of smoking behaviours, they also reported the highest awareness of smoking and passive smoking harms, and were also younger, with a balance between male and female smokers.

A low readiness to quit, coupled with decreased access of supports and services and minimal conversation about quitting, suggests these are smokers had lower receptivity to culturally targeted anti-smoking messages. This lower receptivity was reflected in campaign reaction 
domains. Specifically, this group found all campaign designs to be less thought provoking and personally relevant than other smoker types, particularly the Jack and Michael designs. For the Jack design, one potential explanation for this is that combining smoking cues (i.e. cigarette) and visceral imagery (e.g., eye) can lead to defensive message processing (Clayton, et al., 2017), which can reduce emotional response and message recognition (Leshner, Clayton, Bolls, \& Bhandari, 2018), and may explain the reaction of these smokers.

To address this, campaigns could present counterarguments to barriers that reduce desire to quit, such as the perceived difficulty of quitting, or enjoyment of smoking (Nicholson, Borland, Davey, Stevens, \& Thomas, 2015b). Messaging that highlights the positive association of past attempts with successful future attempts should also be used to promote quitting confidence in these smokers (Vangeli, Stapleton, Smit, Borland, \& West, 2011). It will also be beneficial to examine the impacts of messages that direct smokers to information and services for increasing quit readiness on later receptivity to direct quit support.

\subsection{Ready, connected attempters}

Ready, connected attempters were the most commonly identified type of smokers, differing from others in having spoken with family and friends about quitting in the past six weeks, having attempted at least twice in the past 12 months, and in their intent to try again in the next 12 months. All were highly ready to quit, and despite some allowing smoking in their house, most did not allow smoking in their car. These smokers were middle-aged and predominantly female, with higher social connectedness setting them apart from other types. They reported significantly higher accessing of smoking supports and services, and all had spoken with others about quitting. For these smokers, it was important that their family and friends quit. The role of social connectedness is, however, complex, as it potentially increases exposure to other smokers, which in turn increases perceived difficulty of quitting (Wright, 
2018). The influence of social connectedness on quit attempts should be carefully considered.

Anti-smoking messages for ready, connected attempters should highlight the role of both personal capability and social connections in supporting quit attempts. Given that perceived self-efficacy can increase quit intentions (Gould, Watt, McEwen, Cadet-James, \& Clough, 2015), messaging might show that self-efficacy and social support, alongside nicotine replacement therapies, can increase quit attempts and reduce smoking amount (Bonevski et al., 2018). These findings also reiterate the need for further research regarding the "buddysystem" model for smoking cessation (Faseru, Richter, Scheuermann, \& Park, 2018; May and West, 2000).

These smokers considered all designs highly thought provoking, relevant, believable, concern prompting, and motivating of quitting. Whether the targeted campaign resonated particularly strongly with ready, connected attempters, or their reaction reflects greater readiness to quit requires further examination. These smokers found the Michael design significantly more thought provoking than did unready, potential attempters, suggesting greater resonance with the design. As this may reflect older age smokers identifying with the older age model used in this design, this warrants further examination in messaging.

\subsection{Connected, new attempters}

Finally, one in five smokers were connected, new attempters who planned to quit in the next 12 months, but had not attempted to quit in the 12 months prior. These smokers tended to be middle-aged females, half of whom had spoken with family or friends about quitting, with almost two in five of these smokers having accessed cessation support services. Although these smokers showed a low readiness to quit and low concern about their friends or family quitting, they reported moderately high access of smoking supports and services. 
These smokers may benefit from increased engagement with health services that provide a structured approach to increasing quit readiness. As low quit readiness can be effectively counteracted with pharmacological (i.e. varenicline) and behavioural interventions (Ali, Kaplan, Derefinko, \& Klesges, 2018), messaging should aim to normalise health consultations for accessing such supports. Lower use of pharmacological interventions by socioeconomically disadvantaged smokers would also need to be addressed (Thomas et al., 2015), by promoting subsidised drug prescriptions, for instance. To encourage individual and family health consultation engagement that supports connected, new attempters, anti-smoking messaging can emphasise availability of socially embedded health services that have the trust and respect of community, and offer access to Indigenous Australian staff (Davy et al., 2016). Connected, new attempters responded positively across all reaction domains. However, these smokers considered the Jack design significantly more thought provoking than did the unready, potential attempters. This design presents an image of a child and a child's written message (Figure 1, A), which may resonate well given that half of these smokers had spoken with family and friends about quitting.

\section{Limitations}

Limitations of this study included recruitment, as health services recruitment was reduced by low on-site attendance. Whilst this was anticipated within convenience sampling, future research should use representative sampling. As smaller sample sizes impacted univariate testing power, future designs should ensure enough data are collected for higher power. Yet, as participants are from a difficult to access population, sample data are valuable. The sample was predominantly older and female, with a higher proportion of smokers relative to the South Australian Indigenous population (van der Sterren, et al., 2018). Findings should be interpreted with caution, particularly as participants experienced lower socioeconomic 
advantage due to sampling locations, and social disadvantage is associated with complex barriers to quitting (Pateman et al., 2016).

\section{Conclusion}

Results from this study suggest that the characteristics of Indigenous Australian smokers engaging with culturally targeted anti-smoking social marketing campaigns are relevant to health promotion campaign design. Four types of current smokers were identified based on smoking characteristics, with differences identified in their reaction to campaign designs, particularly whether they were considered thought provoking. Further, non-cross-sectional research is needed to predictively assess the role and impact of targeted anti-smoking campaign designs against these cluster characteristics, and smoking cessation outcomes over time.

\section{Acknowledgements}

The authors thank the Northern and Southern Adelaide Local Health Networks for support in data collection. We also thank all research assistants involved in data collection, as well as all community members completing the survey. This work was supported by SA Health, and Cancer Council SA. Dr A. Daly gave valuable feedback on an earlier manuscript. 


\section{References}

Ali, A., Kaplan, C. M., Derefinko, K. J., \& Klesges, R. C. (2018). Smoking cessation for smokers not ready to quit: Meta-analysis and cost-effectiveness analysis. American Journal of Preventive Medicine, 55(2), pp. 253-262. doi:10.1016/j.amepre.2018.04.021

Australian Institute of Health and Welfare. (2016). Australian Burden of Disease Study: impact and causes of illness and death in Aboriginal and Torres Strait Islander people. https://www.aihw.gov.au/reports/burden-of-disease/illness-death-indigenousaustralians/contents/summary

Australian Institute of Health and Welfare. (2018). Australia's health 2018: In brief. Canberra: AIHW Retrieved from https://www.aihw.gov.au/getmedia/fe037cf1-0cd04663-a8c0-67cd09b1f30c/aihw-aus-222.pdf.aspx?inline=true.

Bonevski, B., Twyman, L., Paul, C., D'Este, C., West, R., Siahpush, M., . . Palazzi, K. (2018). Smoking cessation intervention delivered by social service organisations for a diverse population of Australian disadvantaged smokers: A pragmatic randomised controlled trial. Preventive Medicine, 112, pp. 38-44.

doi:10.1016/j.ypmed.2018.04.005

Clayton, R. B., Leshner, G., Bolls, P. D., \& Thorson, E. (2017). Discard the smoking cueskeep the disgust: An investigation of tobacco smokers' motivated processing of antitobacco commercials. Health Communication, 32(11), pp. 1319-1330. doi:10.1080/10410236.2016.1220042

Davy, C., Cass, A., Brady, J., Devries, J., Fewquandie, B., Ingram, S., . . Brown, A. (2016). Facilitating engagement through strong relationships between primary healthcare and Aboriginal and Torres Strait Islander peoples. Australian and New Zealand Journal of Public Health, 40(6), pp. 535-541. doi:10.1111/1753-6405.12553

Faseru, B., Richter, K. P., Scheuermann, T. S., \& Park, E. W. (2018). Enhancing partner support to improve smoking cessation. Cochrane Database of Systematic Reviews(8)doi:10.1002/14651858.CD002928.pub4 Retrieved from https://doi.org//10.1002/14651858.CD002928.pub4

Foreman, A. K. (1984). Die Latent Class Analyse: Einführung in Die Theorie Und Anwendung [Latent Class Analysis: Introduction to Theory and Application] Weinheim, Germany: Beltz. 
Gould, G. S., McEwen, A., Watters, T., Clough, A. R., \& Zwan, R. v. d. (2013). Should antitobacco media messages be culturally targeted for Indigenous populations? A systematic review and narrative synthesis. Tobacco Control, 22(4), p e7. doi:10.1136/tobaccocontrol-2012-050436

Gould, G. S., Watt, K., McEwen, A., Cadet-James, Y., \& Clough, A. R. (2015). Predictors of intentions to quit smoking in Aboriginal tobacco smokers of reproductive age in regional New South Wales (NSW), Australia: Quantitative and qualitative findings of a cross-sectional survey. BMJ Open, 5(3), p e007020. doi:10.1136/bmjopen-2014007020

Guillaumier, A., Bonevski, B., Paul, C., d'Este, C., Durkin, S., \& Doran, C. (2017). Which type of antismoking advertisement is perceived as more effective? An experimental study with a sample of Australian socially disadvantaged welfare recipients. Tobacco Control, 31(3), pp. 209-216. doi:10.4278/ajhp.141125-QUAN-593

Hardcastle, S. J., \& Hagger, M. S. (2016). Psychographic profiling for effective health behavior change interventions. Frontiers in Psychology, 6doi:10.3389/fpsyg.2015.01988

Hoenig, J. M., \& Heisey, D. M. (2001). The abuse of power: The pervasive fallacy of power calculations for data analysis. The American Statistician, 55(1), pp. 19-24. doi:10.1198/000313001300339897

Kendall, E., \& Barnett, L. (2015). Principles for the development of Aboriginal health interventions: Culturally appropriate methods through systemic empathy. Ethnicity \& Health, 20(5), pp. 437-452. doi:10.1080/13557858.2014.921897

Kubacki, K., \& Szablewska, N. (2017). Social marketing targeting Indigenous peoples: A systematic review. Health Promotion International, 34(1), pp. 133-143. doi:10.1093/heapro/dax060

Leshner, G., Clayton, R. B., Bolls, P. D., \& Bhandari, M. (2018). Deceived, disgusted, and defensive: Motivated processing of anti-tobacco advertisements. Health Communication, 33(10), pp. 1223-1232. doi:10.1080/10410236.2017.1350908

Madill, J., Wallace, L., Goneau-Lessard, K., MacDonald, R. S., \& Dion, C. (2014). Best practices in social marketing among Aboriginal people. Journal of Social Marketing, 4(2), pp. 155-175. doi:10.1108/JSOCM-08-2013-0056 
Maksimovic, L., Shen, D., Bandick, M., Ettridge, K., \& Eckert, M. (2015). Evaluation of the pilot phase of the 'Give up smokes for good' social marketing campaign. Health Promotion Journal of Australia, 26(1), pp. 16-23. doi:10.1071/HE14066

May, S., \& West, R. (2000). Do social support interventions (“buddy systems”) aid smoking cessation? A review. Tobacco Control, 9(4), p 415. doi:10.1136/tc.9.4.415 Retrieved from http://tobaccocontrol.bmj.com/content/9/4/415.abstract

Nicholson, A., Borland, R., Sarin, J., Bennet, P., Davey, M., van der Sterren, A. E., . . Thomas, D. (2017). Associations between advertising recall and quitting in a national cohort of Aboriginal and Torres Strait Islander smokers. Australian and New Zealand Journal of Public Health, 41(4), pp. 444-445. doi:10.1111/1753-6405.12645

Nicholson, A. K., Borland, R., Davey, M. E., Stevens, M., \& Thomas, D. P. (2015a). Past quit attempts in a national sample of Aboriginal and Torres Strait Islander smokers. Medical Journal of Australia, 202(10, Suppl.), pp. S20-S25. doi:10.5694/mja15.00202

Nicholson, A. K., Borland, R., Davey, M. E., Stevens, M., \& Thomas, D. P. (2015b). Predictors of wanting to quit in a national sample of Aboriginal and Torres Strait Islander smokers. Medical Journal of Ausrtalia, 202(10, Supp1.), pp. S26-S32. doi:10.5694/mja15.00199

Noar, S. M., Francis, D. B., Bridges, C., Sontag, J. M., Brewer, N. T., \& Ribisl, K. M. (2017). Effects of strengthening cigarette pack warnings on attention and message processing: A systematic review. Journalism \& Mass Communication Quarterly, 94(2), pp. 416442. doi:10.1177/1077699016674188

O'Cass, A., \& Griffin, D. (2006). Antecedents and consequences of social issue advertising believability. Journal of Nonprofit \& Public Sector Marketing, 15(1-2), pp. 87-104. doi:10.1300/J054v15n01_05

Pateman, K., Ford, P., Fizgerald, L., Mutch, A., Yuke, K., Bonevski, B., \& Gartner, C. (2016). Stuck in the catch 22: Attitudes towards smoking cessation among populations vulnerable to socialdisadvantage. Addiction, 111(6), pp. 1048-1056. doi:10.1111/add.13253

Sanders-Jackson, A. N., Cappella, J. N., Linebarger, D. L., Piotrowski, J. T., O'Keeffe, M., \& Strasser, A. A. (2011). Visual attention to antismoking PSAs: Smoking cues versus other attention-grabbing features. Human Communication Research, 37(2), pp. 275292. doi:10.1111/j.1468-2958.2010.01402 
Stewart, H. S., Bowden, J. A., Bayly, M. C., Sharplin, G. R., Durkin, S. J., Miller, C. L., . . . Wakefield, M. A. (2011). Potential effectiveness of specific anti-smoking mass media advertisements among Australian Indigenous smokers. Health Education Research, 26(6), pp. 961-975. doi:10.1093/her/cyr065

Thomas, D. P., Briggs, V. L., Couzos, S., Panaretto, K. S., Sterren, A. E. v. d., Stevens, M., \& Borland, R. (2015). Use of nicotine replacement therapy and stop-smoking medicines in a national sample of Aboriginal and Torres Strait Islander smokers and ex-smokers. Medical Journal of Australia, 202(10, Suppl.), pp. S78-S84. doi: $10.5694 / \mathrm{mja} 15.00205$

Thomas, D. P., Davey, M. E., Sterren, A. E. v. d., Lyons, L., Hunt, J. M., \& Bennet, P. T. (2019). Social networks and quitting in a national cohort of Australian Aboriginal and Torres Strait Islander smokers. Drug and Alcohol Review, 38(1), pp. 82-91. doi:10.1111/dar.12891

Tsourtos, G., Ward, P. R., Lawn, S., Winefield, A. H., Hersh, D., \& Coveney, J. (2014). Is resilience relevant to smoking abstinence for Indigenous Australians? Health Promotion International, 30(1), pp. 64-76. doi:10.1093/heapro/dau087

Tsourtos, G., Ward, P. R., Miller, E. R., Kathy Hill, Barton, C., Wilson, C. J., \& Woodman, R. (2019). Does resilience moderate the relationship between stress and smoking status? Substabce Use \& Misuse, 54(3), pp. 412-425.

doi:10.1080/10826084.2018.1501066

van der Sterren, A., Greenhalgh, E. M., Knoche, D., \& Winstanley, M. H. (2018). Prevalence of tobacco use among Aboriginal and Torres Strait Islander people. In M. M. Scollo \& M. H. Winstanley (Eds.), Tobacco in Australia: Facts and issues. Melbourne: Cancer Council Victoria. Available from https://www.tobaccoinaustralia.org.au/chapter-8-aptsi/8-3-prevalence-of-tobacco-useamong-aboriginal-peo.

Vangeli, E., Stapleton, J., Smit, E. S., Borland, R., \& West, R. (2011). Predictors of attempts to stop smoking and their success in adult general population samples: a systematic review. Addiction, 106(12), pp. 2110-2121. doi:10.1111/j.1360-0443.2011.03565.x

Wakefield, M. A., Loken, B., \& Hornik, R. C. (2010). Use of mass media campaigns to change health behaviour. Lancet (London, England), 376(9748), pp. 1261-1271. doi:10.1016/S0140-6736(10)60809-4 Retrieved from https://www.ncbi.nlm.nih.gov/pubmed/20933263 
https://www.ncbi.nlm.nih.gov/pmc/articles/PMC4248563/

Wright, A. (2018). Survey of Aboriginal smokers' and ex-smokers' knowledge, attitudes and behaviours in Central Australia 2016-2017. The Australian Journal of Rural Health, 26(4), pp. 251-257. doi:10.1111/ajr.12431 